\title{
Culture, kinship and genes
}

\section{Background}

The central objective of this meeting was to promote future interdisciplinary research into clinical genetics and genetic screening in an ethnically diverse society such as contemporary Britain. To that end, a group of approximately 60 professionals was brought together in Abergavenny for two days (from 28-30 March 1994). The participants were drawn from several professions, predominantly health professionals involved in genetic services or public health medicine, and social or behavioural scientists including social anthropologists, sociologists, and psychologists. It was hoped that there would be sufficient opportunity for informal discussions for participants to initiate proposals for future collaborative research.

\begin{abstract}
Meeting
After arrival on the first evening, two papers were presented. These served the useful role of setting the scene from the perspectives of community genetics (Bernadette Modell) and social anthropology (Marilyn Strathern). Throughout the meeting, reference was continually being made to the themes discussed in these two papers: the diversity of family and marital patterns, and the ubiquity of the concept of "culture" in postindustrial Britain.

The following morning consisted of seven papers and a discussion, with Jeanette Edwards in the chair. The first two papers discussed the concept of "ethnic group" from biological (Helen MacBeth) and social (Ursula Sharma) perspectives. Aamra Darr reported her studies of the networks of kinship, information flow, and family support among British Pakistani families with thalassaemia. Gulshen Karbani reflected on the clinical experience obtained in the genetic counselling service in Leeds and Bradford. Nadeem Qureshi discussed the place of genetics in primary health care, particularly in relation to ethnic minorities. Sue Proctor presented the initial findings from a large study in Bradford, evaluating factors that contribute to adverse birth outcomes among the British Pakistani community. Finally, Charlie Davison presented a paper on the range of lay understandings of inheritance and health in the context of heart disease in South Wales.
\end{abstract}

Members of the Steering Group: Angus Clarke, Department of Medical Genetics, University of Wales College of Medicine, Cardiff; Elizabeth Anionwu, Community Genetics, Institute of Child Health, London; Rohan Burke, Sickle Cell and ThalChild Health, London; Rohan Burke, Sickle Cell and ThalSocial Anthropology, University of Manchester; Gulshen Karbani, Clinical Genetics, Leeds; Theresa Marteau, Psycholog and Genetics, Guy's Hospital, London; Bernadette Modell University College London Medical School; Evelyn Parsons, Medical Genetics, University of Wales College of Medicine, Cardiff; Nadeem Qureshi, Rise Park Surgery, Nottingham.
Everyone attending the meeting will have brought with them their personal and professional perspectives on ethnicity. These papers served to introduce the "biological facts" and "clinical reality" of genetic differences between ethnic groups in Britain from the perspective of clinical genetics, and the social and cultural construction and implication of such "facts" from social science perspectives.

In the afternoon of that day, there were five parallel discussion groups that sought to clarify the scope for future research in the field of "cross-cultural genetics". These smaller groups tackled Interdisciplinary Research (Martin Richards), the Implications of Research and its Findings (Elizabeth Anionwu), Genetic Counselling and Screening in a Multicultural Society (groups led by Robert Mueller and Rohan Burke), and Gender and Genes (Meg Stacey). Representatives from these groups reported back afterwards to the whole group, and a vigorous discussion ensued. What began as a focus on ethnicity in genetic medicine developed as a cross-disciplinary debate illuminating and questioning the premises of the medical and social sciences.

Following this, the MRC guest lecture was given by Professor Olu Akinyanju. The development of genetic counselling services for the haemoglobinopathies in Nigeria was shown to be emerging naturally from a treatment service for these conditions, and pressure to establish genetic screening programmes divorced from concern for the welfare of affected persons was being (so far) effectively resisted. All concurred that there were important lessons here for the provision of genetic services in developed, as well as developing, countries.

There was a discussion of the issues surrounding sex selection in India and a "eugenics" programme in China, which was again useful in making all present aware of the different perspectives that we brought to the field of genetics. The question was raised as to whether different economic circumstances and needs in developing countries justify the adoption of different goals and methods in genetic screening from those invoked in the West.

On the final morning, there were three stimulating papers followed by lengthy discussions. The papers addressed political and social issues: the social consequences of genetic screening programmes in general, and in particular their effects on those with disabilities and on women. The ensuing discussion was wide ranging and challenging. In the final session of the morning, the discussion was steered back to the question of our agendas for future research. Several participants outlined their 
thoughts on where social research into genetic issues should be directed, and how research which was conducted in an ethnically sensitive manner could both improve clinical services to diverse populations and provide a more fundamental understanding of the social and cultural implications of genetic disease and genetic medicine.

\begin{abstract}
Assessment
It is not possible to evaluate the success of this meeting so soon, when it will necessarily take some years for the dialogue between professions to mature into research proposals, and for these proposals to mature into completed studies. However, there has already been a lot of feedback indicating that many participants found the event useful. They have made promising contacts in other disciplines and these are leading towards the construction of proposals for future, interdisciplinary research. The immediate reaction to the meeting on the part of many participants has been that it was stimulating and provoked thought, and the need for future research was clearly shown. The organisers, however, had not anticipated that the inevitable interdisciplinary differences would dominate the discussions in the second half of the meeting to the extent that they did. The awareness of interdisciplinary differences that began to emerge will clearly be very important in shaping future collaborative studies in this field. Two interrelated areas of potential dispute that will need to be resolved in any collaboration are:
\end{abstract}

(1) Who sets the agenda? The distinct traditions of clinical research and social science research mean that they address different questions and use different methodologies. The established dominance of the clinical perspective so far needs to be acknowledged.

(2) There is a conflict between the need for fundamental research, and the requirements of the clinician whose aim is to improve services without necessarily questioning the premises on which they are based.

It is important to acknowledge the potential for these "cross-disciplinary" conflicts in advance. In this way, and with understanding and goodwill on all sides, it will be possible to design research that addresses questions from the research agendas of at least two different professions.

In resolving these potential conflicts, it will be seen that truly interdisciplinary research is more powerful, more productive, and much more exciting than mere research-in-parallel on similar topics or projects. Interdisciplinary research is synergistic, generating much more than the sum of the parts.

In addition to the fostering of personal contacts, the other short to medium term achievement of the meeting will, we hope, be the publication of papers presented at Abergavenny.

\section{Conclusion}

In summary, then, the meeting certainly achieved its goal of establishing contacts and initiating discussions between the different disciplines interested in cross-cultural genetics. A dialogue was begun that will, we hope, be very fruitful. It is not possible to know how successful the meeting will prove to have been in terms of future research undertaken, but we are optimistic that important links have been established that are likely to be productive. We are planning to hold a second meeting in two years' time, and anyone interested should contact Angus Clarke at the address below.

ANGUS CLARKE Institute of Medical Genetics, University of Wales College of Medicine Heath Park, Cardiff CF4 4XN, UK. 